\title{
Emergence of lymphogranuloma venereum in Canada
}

\author{
Fast-tracked article. Published at www.cmaj.ca on May 31, 2005.
} Jumphogranuloma veneretransmitted infection (STI) caused by Chlamydia trachomatis serotypes L1, L2 and L3. Unlike other serotypes (A to $\mathrm{K})$, those that cause LGV are invasive and preferentially target lymph tissue. LGV can be transmitted through vaginal, anal or oral sexual contact and can be prevented through the use of condoms or other barrier methods.

LGV infection begins with a small, painless lesion (which may go unnoticed) and can progress to painful enlargement of local lymph nodes, which may coalesce to form a bubo. ${ }^{1}$ If the infection is left untreated, lymphatic obstruction may result, which can lead to serious complications, such as destruction of the genitals or rectum (including rectal stricture), and can uncommonly lead to meningoencephalitis, hepatitis and death. As with other STIs, the presence of LGV increases the risk for acquisition and transmission of HIV infection, other STIs and other conditions caused by bloodborne pathogens, such as hepatitis $\mathrm{C}$.

Until recently, LGV was rare in industrialized countries, although it is endemic in parts of Africa, Asia, South America and the Caribbean. ${ }^{2}$ However, cases in men having sex with men have been reported recently in Europe (starting in 2003 in the Netherlands, and additional cases being reported from Belgium, France, Germany, Sweden and Britain); - cases have also been reported r recently from the United States. These cases have been associ: ated with concurrent HIV inof fection and hepatitis C, sex parties and higher-risk sexual activities (e.g., "fisting"). ${ }^{3}$

C. trachomatis infection is re- portable in all provinces and territories in Canada, but only some provinces break down their surveillance data into cases caused by LGV serotypes and those caused by non-LGV serotypes. To monitor LGV in

this country, the Public Health Agency of Canada (PHAC) has established a national surveillance system for LGV in partnership with the provinces and territories, which began in February 2005 . The surveillance
Box 1: Case definition of lymphogranuloma venereum (LGV) used for surveillance in Canada

\section{Probable case}

Positive result of culture, nucleic acid amplification testing (NAAT) or serologic testing for Chlamydia trachomatis plus the presence of proctitis OR inguinal or femoral lymphadenopathy OR a sexual partner with LGV

Confirmed case

Presence of C. trachomatis serotype L1, L2 or L3 confirmed by DNA sequencing or restriction fragment length polymorphism

Notes

- A positive serologic test result is defined as a high microimmunofluorescence titre $(\geq 1: 256)$ or a high complement fixation titre $(\geq 1: 64)$.

- Cases that otherwise fit the probable definition are not considered probable when the results of confirmatory (genotype) testing for LGV serotypes are negative, but they are considered probable when the results are inconclusive.

- When possible in suspected cases of LGV, both a swab and serum sample should be submitted for laboratory testing. Physicians should contact their local laboratory or the National Microbiology Laboratory (Heidi_Wood@phac-aspc.gc.ca) for more information and advice on specimen collection and transport.

- NAAT is not officially approved in Canada for use with rectal or oropharyngeal swabs. Repeat testing is advised to confirm a positive result.

- The case definition was developed by the Public Health Agency of Canada in partnership with the Expert Working Group for the Canadian STI Guidelines and the Provincial and Territorial STI Directors.

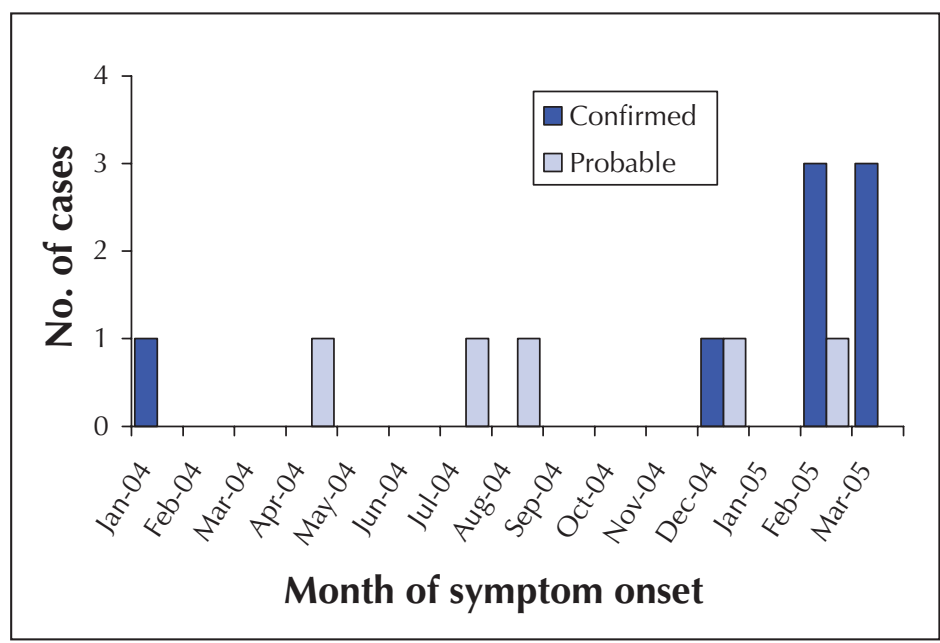

Fig. 1: Epidemic curve of the 13 cases in Canada of lymphogranuloma venereum reported to the Public Health Agency of Canada for which the date of symptom onset was known. 
protocol, case definition and recommended treatment will be available as of June 5, 2005, at www.phac-aspc.gc.ca/std-mts.

\section{Epidemiologic features}

Box 1 presents the case definition used in Canada for national surveillance. Because culture and nucleic acid amplification testing (NAAT) do not distinguish between LGV and nonLGV serotypes, and because a high microimmunofluorescence titre ( $\geq 1: 256$ ) or a high complement fixation titre $(\geq 1: 64)$ only suggests $L G V$, a positive result with one of these methods requires confirmation with an LGV-specific test (restriction fragment length polymorphism or DNA sequencing).

As of May 13, 2005, 22 LGV cases had been reported to the PHAC; 6 were probable and 16 confirmed according to the case definition. All genotyped strains of $C$. trachomatis were L2b, similar to the outbreak strain in the Netherlands. Of the 13 cases for which the date of symptom onset was known, the earliest onset was in January 2004 and the most recent on Mar. 21, 2005 (Fig. 1).

Epidemiologic data were available for 19 of the cases (Table 1). The cases appear to be unlinked. All 19 cases were among men. Proctitis and inguinal lymphadenopathy were the most common presenting symptoms. Of the 8 patients concurrently infected with HIV, 3 also had hepatitis C; for only 1 of these 3 men was historical information available on behaviour placing the patient at increased risk of hepatitis $\mathrm{C}$ (sharing injection drug equipment, fisting and rectal use of methamphetamine in the 60 days before interview).

Of the 19 men, 12 reported having had sexual contact in the 60 days before their interview, 10 with male partners only (1-16 partners) and 1 with female partners only (2 partners); the remaining patient did not disclose partner information. Most often (in 6 [86\%] of the 7 cases for which this information was available), sexual contact occurred in a private residence; bathhouse contact was reported by 4 men (33\% of the 12) and finding partners on the Internet by 5 men ( $42 \%$ of the 12 ). None of the men reported having a sexual partner with known LGV. Although 2 of the men reported having had sex while travelling within Canada in the 60 days before their interview, none reported having had sex while travelling outside of Canada in this time frame.

\section{Controlling transmission}

Efforts to control the transmission of LGV include prevention, early diagnosis and appro-
Table 1: Summary of epidemiologic features of 19 reported cases of lymphogranuloma venereum

\begin{tabular}{|c|c|}
\hline Feature* & No. $(\%)$ of cases $†$ \\
\hline Age range, yr & $29-47$ \\
\hline Male & $19 / 19(100)$ \\
\hline \multicolumn{2}{|l|}{ Ethnicity } \\
\hline White & $10 / 12 \quad(83)$ \\
\hline Asian & $1 / 12$ \\
\hline South American & $1 / 12$ \\
\hline \multicolumn{2}{|l|}{ Presenting symptoms $\ddagger$} \\
\hline Proctitis & $11 / 14 \quad(78)$ \\
\hline Inguinal lymphadenopathy & $6 / 14 \quad(43)$ \\
\hline Malaise & $4 / 14 \quad(28)$ \\
\hline Genital papule or lesion & $3 / 14 \quad(21)$ \\
\hline Rectal discharge or pain & $3 / 14 \quad(21)$ \\
\hline Swollen testicles & $1 / 14 \quad(7)$ \\
\hline Abdominal pain & $1 / 14$ \\
\hline Swollen neck & $1 / 14 \quad(7)$ \\
\hline Constipation & $1 / 14$ \\
\hline \multicolumn{2}{|l|}{ Concurrent infection $\neq$} \\
\hline HIV infection & $8 / 11 \quad(73)$ \\
\hline Hepatitis C & $3 / 12 \quad(25)$ \\
\hline Gonorrhea & $2 / 13 \quad(15)$ \\
\hline Genital herpes & $6 / 13 \quad(46)$ \\
\hline Syphilis & $3 / 14 \quad(21)$ \\
\hline $\begin{array}{l}\text { Sexual contact within } 60 \mathrm{~d} \\
\text { before interview }\end{array}$ & 12/14 (86) \\
\hline Condom not used & $6 / 12 \quad(50)$ \\
\hline \multicolumn{2}{|l|}{ Type of sexual contact $\ddagger$} \\
\hline Anal sex & $10 / 12 \quad(83)$ \\
\hline Oral sex & $10 / 12 \quad(83)$ \\
\hline Vaginal sex & $1 / 12$ \\
\hline "Fisting" & $2 / 11 \quad(18)$ \\
\hline "Rimming" & $(22)$ \\
\hline Use of sex toys & $(22)$ \\
\hline \multicolumn{2}{|l|}{ Circumstances of sexual contact } \\
\hline Private residence & $6 / 7 \quad(86)$ \\
\hline Internet partnering & $5 / 12 \quad(42)$ \\
\hline Bathhouse & $4 / 12 \quad(33)$ \\
\hline "Rave" or "circuit party" & $2 / 12 \quad(17)$ \\
\hline Sex trade & $1 / 12$ \\
\hline "Leather scene" & $1 / 12$ \\
\hline $\begin{array}{l}\text { Sexual contact occurred while } \\
\text { travelling outside reporting jurisdiction }\end{array}$ & $2 / 10 \quad(20)$ \\
\hline
\end{tabular}

*Information was not available for all features in all cases. †Unless stated otherwise.

$\ddagger$ More than 1 answer could be given for an individual case. 
priate treatment of the patient and sexual partners (Box 2). Diagnosis, often based on history and the clinical picture, can be difficult, given that the symptoms overlap with those of other STIs and other infections or conditions. Specialized testing for LGV can assist in diagnosis; whenever possible in suspected cases, both a swab (for culture or NAAT) and serum sample (for microimmunofluorescence or complement fixation testing) should be submitted. Some local laboratories are able to test specifically for LGV, whereas others would need to involve the National Microbiology Laboratory through their provincial laboratory. Physicians should contact their local laboratory or the National Microbiology Laboratory (Heidi_Wood@phac -aspc.gc.ca) for more information on collection, transport and testing of specimens.

In suspected cases, empiric treatment should be given for LGV (and for gonorrhea when clinically indicated) while the test results are awaited. Counselling and testing for other STIs, including HIV infection, hepatitis B and hepatitis $C$, are also recommended in such cases, given the rates of concurrent infection.

Cases of LGV should be reported to local health authorities. Currently in Canada, LGV appears to be primarily occur-

\section{Box 2: Recommended treatment of lymphogranuloma venereum in Canada}

\section{First line}

Doxycycline, $100 \mathrm{mg}$ orally twice daily for 21 days

\section{Alternative}

Erythromycin base, $500 \mathrm{mg}$ orally 4 times daily for 21 days. Equivalent dosages of other formulations may be substituted, except that the estolate formulation is contraindicated during pregnancy

\section{Possible}

Azithromycin, $1 \mathrm{~g}$ orally once weekly for 3 weeks. Although some experts believe azithromycin to be effective in the treatment of lymphogranuloma venereum, clinical data are lacking

Notes

- Sexual partners within preceding 60 days should be contacted and treated with either doxycycline, $100 \mathrm{mg}$ orally twice daily for 7 days, or azithromycin, 1 g orally in a single dose.

- Aspiration of a bubo may help to relieve symptoms; however, incision and drainage or excision of nodes is not helpful and may delay healing.

- The treatment recommendation was developed by the Public Health Agency of Canada in partnership with the Expert Working Group for the Canadian STI Guidelines and the Provincial and Territorial STI Directors.

ring among men having sex with men, a high proportion of whom have concurrent HIV infection, other STIs or hepatitis C. LGV is an emerging and significant public health concern.

\section{Rhonda Y. Kropp}

Senior Public Health Analyst

Sexual Health and Sexually

Transmitted Infections Section

\section{Thomas Wong}

Director

Community Acquired Infections

Division

Centre for Infectious Disease

Prevention and Control

Public Health Agency of Canada

Ottawa, Ont.

On behalf of the Canadian LGV

Working Group

Acknowledgement: We thank the following members of the Canadian LGV Working Group for their critical involvement in both the collection of the enhanced surveillance data and the review and revision of the manuscript: Maritia Gully, Hugh Jones, Grant McClarty, Janice Mann, Gina Ogilvie, Frank Plummer, Michael Rekart, Lorraine Schiedel, Susanne Shields, Ameeta Singh, Marie Carole Toussaint, Sylvie Venne and Heidi Wood.

\section{References}

1. Weir E. Lymphogranuloma venereum in the differential diagnosis of proctitis. CMA7 2005;172(2): 185 .

2. Bauwens JE, Orlander H, Gomez MP Lampe M, Morse S, Stamm WE, et al. Epidemic lymphogranuloma venereum during epidemics of crack cocaine use and HIV infection in the Bahamas. Sex Transm Dis 2002;29:253-9.

3. Gotz H, Nieuwenhuis R, Ossewaarde T, Bing Thio $H$, van der Meijden W, Dees J, et al. Preliminary report of an outbreak of lymphogranuloma venereum in homosexual men in the Netherlands, with implications for other countries in western Europe. Eurosurv Wkly 2004;8(4). Available: www.euro surveillance.org/ew/2004/040122.asp\#1 (accessed 2005 May 25).

\section{Clinical trial registration}

CMAJ will consider clinical trials for publication only if they have been registered in a publicly accessible clinical trials registry before the enrolment of the first patient. This policy applies to trials that start recruiting on or after July 1, 2005. For trials that began enrolment before this date, registration is required by Sept. 13, 2005. The criteria for acceptable registration are described in CMAJ $(2005 ; 172[13]: 1700-2)$. 